\title{
A RELAÇÃO ENTRE O DIREITO E AS ARTES: Contribuições Para o Pensamento Crítico Contemporâneo
}

http://dx.doi.org/10.21527/2176-6622.2020.53.18-27

Recebido em: 19/7/2019

Modificações solicitadas em: 20/1/2020

Aceito em: 24/1/2020

Alejandro Knaesel Arrabal

Doutor em Direito Público pela Universidade do Vale dos Sinos - Unisinos. Mestre em Ciências Jurídicas pela Universidade do Vale do Itajaí - Univali. Especialista em Direito Administrativo pela Universidade Regional de Blumenau - Furb. Professor de Metodologia da Pesquisa em Cursos de Especialização da Furb. Professor de Direito da Propriedade Intelectual e Metodologia da Pesquisa Jurídica do Curso de Graduação em Direito da Furb. Professor de Direito Administrativo do Curso de Graduação em Direito do Centro Universitário de Brusque - Unifebe. Líder do grupo de pesquisa Direito, Tecnologia e Inovação - DTIn (CNPq-Furb). Membro dos grupos de pesquisa Constitucionalismo, Cooperação e Internacionalização Constinter - e Estado, Sociedade e Relações Jurídicas Contemporâneas (CNPq-Furb). Membro do Núcleo de Inovação Tecnológica (NIT) da Furb. http://lattes.cnpq.br/0957562986221644. http://orcid.org/00000002-0927-6957. arrabal@furb.br

Carlos Eduardo do Nascimento

Pós-graduando do curso Filosofia e Teoria do Direito da universidade PUC Minas. Graduado em Direito pela Universidade Regional de Blumenau - Furb. Pesquisador do grupo de pesquisa "Política Constitucional e Novas Juridicidades: desvelando práticas sociais emancipadoras". http://lattes.cnpq.br/5031578938045608. https:// orcid.org/0000-0003-3243-0972. carloseduardo@acnquimica.com.br

\section{RESUMO}

A Criticidade, como a face visível da crise paradigmática do positivismo jurídico, surge em resposta aos problemas oriundos das limitações da Teoria Tradicional do Direito, tendo como principal objetivo a emancipação do Direito como indutor das transformações sociais. Destarte, o Direito desenvolve a Teoria Crítica, acrescendo a perspectiva social à observação jurídica, a fim de oferecer respostas concretas à sociedade. Por sua vez, expressões artísticas podem conter um apelo crítico intenso que instiga profundas reflexões no contexto social, a partir dos mais variados estudos e campos do saber - incluindo o jurídico. Tendo em vista o seu caráter crítico-reflexivo, a Arte oferece ao Direito releituras interdisciplinares que oportunizam uma compreensão mais plena e reflexiva do fenômeno jurídico. Desenvolvido por meio de revisão bibliográfica e sob perspectiva interdisciplinar, este artigo procura demonstrar como o diálogo entre o Direito e as Artes oportuniza denúncias metafóricas da realidade, de modo a expandir o pensamento crítico social e jurídico.

Palavras-chave: Direito. Arte. Pensamento crítico. Criticidade.

\section{THE RELATIONSHIP BETWEEN LAW AND THE ARTS: CONTRIBUTIONS TO CONTEMPORARY CRITICAL THINKING}

\section{ABSTRACT}

Criticism, as a visible face of the paradigmatic crisis of legal positivism, emerges as a response to the problems arising from the limitations of the Traditional Theory of Law, whose main objective is the emancipation of Law as an inducer of social transformations. Thus, Law develops the Critical Theory, adding the social perspective to legal observation, in order to offer concrete answers to society. In turn, artistic expressions can contain an intense critical appeal that instigates deep reflections in the social context, from the most varied studies and fields of knowledge - including juridical. Considering the reflective character that integrates Art, it is unequivocal the availability to the Law, interdisciplinarily, of re-readings that allow a fuller and more reflective understanding. Developed through bibliographic review and from an interdisciplinary perspective, this work aims to demonstrate how the dialogue between the Law and the Arts provides metaphorical denunciations of reality, in order to expand critical social and legal thinking.

Keywords: Law. Art. Critic Thought. Criticism.

\section{SUMÁRIO}

1 Introdução. 2 Considerações acerca da arte, da cultura e sua relação com a crítica. 3 Teoria Crítica do Direito. 4 Direito e Arte na perspectiva crítica. 5 Conclusão. 6 Referências. 


\section{INTRODUÇÃO}

Na perspectiva originária do Direito moderno, quando o poder de interpretação e articulação das leis passa das mãos de um monarca absolutista para um Estado consolidado, nasce o positivismo exegético, que apresenta problemas referentes a um univocismo semântico e estritamente legalista. Para superar tais disfunções fundadas em crises paradigmáticas, emerge a proposta de um normativismo positivista.

Por mais que o positivismo de Kelsen parecesse tratar eficientemente todos os vícios do "ser" com os paradigmas do "dever ser coercitivo", em um dado momento, também entra em conflito com as expectativas sociais. Com os graves conflitos vivenciados internacionalmente pela sociedade no final da primeira metade do século 20, emerge a necessidade de o Direito se desenvolver e se adequar ao panorama dos novos tempos. Nessa perspectiva, surge uma criticidade inerente à prática do Direito em sintonia com as requisições sociais, trazendo como ideia basilar a quebra da mera concepção técnico-formal que privilegia a exclusão e desigualdade para promover uma abordagem emancipadora do Direito e a consequente transformação social. Este panorama origina a Teoria Crítica do Direito.

Em contrapartida, em outro viés teórico de outro cariz que não o jurídico, desenvolve-se a teoria artística, com manifestações cada vez mais complexas em perspectivas, muitas vezes, oblíquas. Considerando a obliquidade da Arte diante da realidade social, instaura-se a possibilidade de a manifestação artística figurar como promotora do pensamento crítico. Seja em uma poética bem estruturada, que denuncia penumbras sociais hostis às relações democráticas, seja em uma canção que retrata de modo irônico e metafórico os problemas sociais, a Arte dialoga com a realidade de modos diversos. Afirma Eco (2016, p. 39) que "o artista não pode se abstrair, como pura vontade criativa, do contexto social em que vive".

É nesta encruzilhada, portanto, que este ensaio procura demonstrar como o diálogo entre o Direito e as Artes oportuniza denúncias metafóricas da realidade, de modo a expandir o pensamento crítico.

Desenvolvido a partir de revisão bibliográfica e sob perspectiva interdisciplinar, o estudo foi estruturado em três partes. A primeira aborda os conceitos de Arte e Cultura e sua relação com a crítica. A segunda trata do esgotamento do racionalismo positivista no Direito e a importância do pensamento jurídico crítico. A terceira e última parte explora o diálogo entre o Direito e as Artes, destacando, a partir de diversos exemplos, como esta aproximação é emancipatória e promotora de reflexões transformadoras.

\section{CONSIDERAÇÕES ACERCA DA ARTE, DA CULTURA E SUA RELAÇÃO COM A CRÍTICA}

Arte e Cultura são categorias que se entrecortam. A materialidade do universo social, com todas as suas possibilidades, expectativas e olhares, é produto de um agir coletivo que se manifesta de modo difuso, plural e, não raras vezes, contraditório. Instituições como a família e o Estado são produtos do "culto" (do "cultivo"), entendido como as práticas habituais que se consolidam no plano histórico. A Arte é uma das dimensões protagonistas da realidade social. Do seu étimo latino, compreende o movimento do corpo, da "raiz 'ar' de artus (articulação), e de armus (úmero, que dá igualmente o sentido de movimento)" (RUGIU, 1998, p. 31). Trata-se da "articulação" humana que, ao dialogar com o mundo, faz emergir novas formas, produzidas e interpretadas a partir de um plano de significações e valores. Williams (apud CRISTELLI, 2013, p. 35) observa que a cultura compreende um "sistema de significações mediante o qual necessariamente uma dada ordem social é comunicada, reproduzida, vivenciada e estudada". Para tanto a Arte, na qualidade de manifestação, é determinante para a sociabilidade, visto que comunica as vivências e realidade humana que, por sua vez, constituem a Cultura.

Tolstoi (2016) considera que "A arte é a atividade humana que consiste em um homem comunicar conscientemente a outros, por certos sinais exteriores, os sentimentos que vivenciou, e os outros serem contaminados por esses sentimentos e também os experimentar." O escritor russo adota a "contaminação" como o critério para arte. O termo contaminação pressupõe propagação, compartilhamento que, por sua vez implica interpretação. Nesse sentido, a substância da manifestação artística resulta de uma espécie de "lente psíquica" do artista que transmuta a realidade e a contamina. Segundo Tolstoi (2016), "a boa arte é a que comunica aos outros a vivência pelos artistas dos sentimentos do bem, de forma que eles sejam contaminados pelo 
mesmo sentimento". Afirma ainda que "O bem é eterno, o objetivo mais alto de nossa vida. Não importa como o entendamos, nossa vida não é senão um esforço em direção ao bem. [...] O bem é aquilo que ninguém pode definir, mas que define tudo o mais" (TOSTOI, 2016).

Nesta perspectiva, a Arte está comprometida com a promoção do bem. Para Tolstoi, por mais que a Arte direcione o intérprete para o caminho do bem, o bem em pauta é aquele que o autor da obra artística define, contempla e interpreta, o que, por si só, pressupõe subjetividade. A oração citada anteriormente "Não importa como o entendamos [o bem]" destaca tal compreensão. Consolidando o pensamento de Tolstoi, e acrescentando uma interpretação mais contemporânea e prática, Eco (2016, p. 272) assim considera:

É possível que, diante de uma obra de arte, eu compreenda os valores que ela comunica e que, ainda assim, não os aceite. Nesse caso, posso discutir uma obra de arte no plano político e moral e posso rejeitá-la, contestá-la justamente porque é uma obra de Arte. Isso significa que a Arte não é o absoluto, mas uma forma de atividade que estabelece uma relação dialética com outras atividades, outros interesses, outros valores. Diante dela, na medida em que reconheço a obra como válida, posso operar minhas escolhas, eleger meus mestres. A tarefa do crítico pode ser também e especialmente esta: um convite a escolher e a discernir. Cada um de nós, lendo uma obra literária, ainda que professe os critérios técnico-estruturais aqui expostos, pode e deve encontrar uma relação emocional e intelectual, descobrir uma visão do mundo e do homem. É justo que existam pessoas com a sensibilidade mais apurada que nos comuniquem as suas experiências de leitura para que possam se tornar nossas também.

Eco decifra a compreensão do âmago artístico: a Arte não é o absoluto. A Arte é produto de uma dimensão "valorativa" que oportuniza a dialética entre autores e intérpretes, tendo a materialidade da expressão artística como mediadora. É neste campo que a crítica se faz possível e necessária, uma vez que a realidade cultural, constituída a partir do protagonismo artístico, não se coaduna com o absoluto.

Ao figurar como "espelho" das concepções de mundo e aspirações, a Arte plasma as contradições da existência humana. Ao produzir e contemplar suas criações, a humanidade encontra modos para lidar com a vida que não estão absolutamente presos à objetividade material. Espelhar-se na Arte é também testemunhar o verso de si. No plano das expressões artísticas há lugar para a beleza das formas precisas e estáveis, bem como para rupturas e descontinuidades, para o ilógico e o irracional. Assim, por meio da Arte, a crítica social torna-se possivel.

A dimensão artística compreende um espaço simbólico de figuração e transfiguração da existência. $O$ senso artístico aponta tanto para o real como também para o imaginário e a negação da realidade posta, ou seja, configura-se como um horizonte que revela alternativas existenciais, comportando, inclusive, a crítica dos seus próprios estatutos. Foi assim com o dadaísmo, movimento do início do século 20 que propôs uma nova concepção de Arte, colocando sob suspeita a própria figura do artista em defesa da desconstrução da estética então vigente (KOBS, 2010).

Refletir sobre a realidade social (e jurídica) por meio da Arte é enfrentar o desafio de perceber a existência para além das obviedades produzidas pela mimese. A Arte traduz o esforço de representação da vida e, nesse sentido, qualifica-se como produto de atividades miméticas. A Arte, porém, não se limita a isso, do contrário seria mera reprodução técnica, desprovida da "aura artística", como afirmou Benjamin (1987).

Já nas sociedades primitivas a Arte era percebida como expressão da coletividade, "[...] o coletivo significava a vida e o conteúdo da vida. A arte, em todas as suas formas - a linguagem, a dança, os cantos rítmicos, as cerimônias mágicas - era a atividade social por excellence, comum a todos e elevando todos os homens acima da natureza, do mundo animal" (FISCHER, 1979, p. 47). Na qualidade de produto social, a Arte incorpora as inquietações da vida, revelando seu cariz crítico.

Alguns exemplos de reflexão social crítica obtidas por meio da Arte podem ser eleitos para observação, tendo em vista as preocupações e dilemas que exploram. Marisa Naspolini e Miriam Pillar Grossi proporcionaram uma experiência de artes cênicas em escolas de Santa Catarina, em que buscaram discutir questões referentes a gênero, levantando, inclusive, a questão da violência. Para as professoras, a Arte pode tratar sobre questões de gênero a ponto de abrir a "possibilidade de uma apreensão e discussão destas temáticas por vias mais sensoriais" (NASPOLINI; GROSSI, 2017, p. 88). 
[...] foi consensual o reconhecimento da importância de uma prática artística que possibilitasse um trabalho psicofísico, resultando em grande interação e integração no coletivo, além de um mergulho autobiográfico que gerou uma percepção encarnada da alteridade. Ao partir de si, cada integrante pôde colocar-se com maior propriedade no lugar do outro e refletir com maior profundidade sobre a experiência vivida na escola, de forma mais consciente, complexa e integrada (NASPOLINI; GROSSI, 2017, p. 90).

Neste caso, observa-se que a Arte oportuniza ao intérprete a compreensão do mundo pela experiência sensorial, desenvolvendo um senso de empatia com a realidade alheia. A Arte transcende a inutilidade do belo ao comportar também uma dimensão funcional. Ionesco (apud ORDINE, 2016, p. 18) afirma que "se não se compreende a utilidade do inútil e a inutilidade do útil, não se compreende a arte". Nesse sentido, pode-se afirmar que há uma utilidade da Arte quanto ela oportuniza uma experiência reflexiva que coloca, autores e intérpretes, em condições de promover um efetivo diálogo crítico.

\section{TEORIA CRÍTICA DO DIREITO}

Os poderosos controlam as vidas dos sem poder. É assim que o mundo funciona. É injusto e desleal.

O trecho supracitado trata de uma passagem do filme Capitão Fantástico, de Matt Ross (CAPITÃO FANTÁSTICO 2016), descrita por Ben, personagem interpretado pelo ator Viggo Mortensen. O trecho destaca quão relevante é o debate a respeito (e a partir) do pensamento crítico tendo em vista as relações de poder, especialmente no campo jurídico.

A sociedade do século 20 (notadamente da primeira metade), com a consolidação das vias positivistas de uma normatividade estruturada que respondia aos vícios da exegese, apresentava dificuldades e desigualdades avassaladoras. Tais dificuldades, porém, não eram vistas como estudos de interesse ou competência do Direito, pois, para o positivismo jurídico, só o positivo é real. Bobbio (2006, p. 135) afirma que:

O positivismo jurídico nasce do esforço de transformar o estudo do Direito numa verdadeira e adequada ciência que tivesse as mesmas características das ciências físico-matemáticas, naturais e sociais. Ora, a característica fundamental da ciência consiste em sua avaloratividade, isto é, na distinção entre juízos de fato e juízos de valor. [...] A ciência exclui do próprio âmbito os juízos de valor, porque ela deseja ser um conhecimento puramente objetivo da realidade [...].

Durante muito tempo (e até mesmo na atualidade) a ciência ambicionou "disciplinar a aparente complexidade dos fenômenos a fim de revelar a ordem simples a que eles obedecem. Mas resulta que os modos simplificadores de conhecimento mutilam mais do que exprimem as realidades ou os fenômenos de que tratam" (MORIN, 2011, p. 5).

Observa Coelho (2003, p. 407) que o modelo positivista sintetiza "três pressupostos ideológicos básicos, nos quais radica toda a concepção dogmática do Direito, na condição de fundamentais", sendo estes "o da unicidade, o da estatalidade e o da racionalidade". Assim, o positivismo consolida-se como conjunto de conhecimentos que estabelece as bases e conforma a Teoria Tradicional do Direito. Esta Teoria representa uma das faces do Direito moderno vinculada a um "racionalismo metafísico-natural" e a um "racionalismo lógico-instrumental" (WOLKMER, 2015, p. 27). Para Trilling (2015, p. 18-19),

[...] quando dizemos que determinado pensador está comprometido com o racionalismo, queremos exprimir [...] que ele concebe o universo e o homem de maneira simplista e de que seu pensamento parte do princípio de que há analogia próxima a ser traçada entre o homem e a máquina. Não obstante essa analogia fundamentasse, para alguns, certo otimismo quanto ao controle e a direção da vida, para outros ela foi causa de angústia profunda, dado que parecia limitar a liberdade e a dignidade humanas.

Ao observar a abrangência destes postulados para o Direito moderno, constata-se, inicialmente, que o racionalismo lógico-instrumental passa a ser a razão principal de sua vinculação e institucionalização moderna. Considerando que o Direito compreende o "fato social, um mecanismo de dominação, um fator da 
ação social" (SCREMIN, 2004, p. 149), sua instrumentalização moderna, obviamente, destina-se a fortalecer e atender aos interesses de classes específicas dotadas de poder, capazes de tornar a expressão jurídica um instrumento de controle e dominação social.

Nesse sentido, o Direito contribui para mantença dos interesses dos "poderosos", controlando a vida dos "sem poder" de forma dogmatizada, por vezes de modo indireto, por omissão, preservando a "obediência cega" como única plataforma de compreensão do Direito Estatal, sem apontar outras possibilidades que não se coadunem com o próprio formalismo técnico de viés cientificista. O Direito positivo passa a não mais responder às demandas sociais, fazendo com que uma criticidade insurja entre seus flancos na busca por medidas autolegitimadoras.

A importância da discussão sobre o "pensamento jurídico crítico" é plenamente justificada, porquanto o modelo de cientificidade que sustenta o discurso jurídico liberal-individualista e a cultura normativista tecno-formal está em processo de profundo esgotamento (WOLKMER, 2015, p. 21).

No processo de esgotamento do modelo jurídico tradicional, surgem formas e paradigmas alternativos que buscam a emancipação do Direito, observando com maior abrangência e realismo o mundo no qual a interpretação e atuação se darão. Nesse contexto surge o pensamento jurídico essencialmente crítico. De forma genérica, ao retratar o pensamento jurídico crítico como forma alternativa de racionalismo humano, pode-se entender que suas pretensões giram em torno de

[...] repensar, dessacralizar e romper com a dogmática lógico-formal imperante numa época ou num determinado momento da cultura jurídica de um país, propiciando as condições e os pressupostos necessários para o amplo processo estratégico/pedagógico de "esclarecimento", "autoconsciência", "emancipação" e "transformação" da realidade social (WOLKMER, 2015, p. 21).

Por certo, pode-se entender que a crítica compreende o "conhecimento que não é dogmático, nem permanente, (mas) que existe num contínuo processo de fazer-se a si próprio" (WOLKMER, 2015, p. 29). Desenvolvendo-se, portanto, a crítica como a emancipação do dogmatismo do conhecimento, para um conjunto de conhecimentos que consolidem uma teoria plena, entende-se o paradigma crítico teorizado como aquele "com um certo tipo de ação que resulta na transformação da realidade", indicando que "somente uma teoria 'crítica' pode resultar na libertação do ser humano, pois não existe transformação da realidade sem a libertação do ser humano" (WOLKMER, 2015, p. 29).

Nas palavras de Coelho (2003), então, "fica assim definido o contexto da teoria crítica do direito como a união dialetizada entre a teoria e a experiência, na realização do direito como espaço de luta e conquista com vistas à autonomia dos indivíduos e à emancipação das sociedades".

As expressões críticas do Direito, na condição de teorias plenamente consolidadas, são muitas. Para este estudo, porém, considera-se a questão crítica que norteia o Direito como manifestação criticista emancipatória em sentido amplo, pois a teoria crítica aponta para um processo de libertação, transformação e emancipação, como já referido. O que se considera aqui é a perspectiva transformadora do Direito por meio da Arte, na condição de expressão crítica que desencadeia a emancipação de processos de controle epistêmicos voltados à produção e reprodução do conhecimento e à conformação da própria realidade.

\section{DIREITO E ARTE NA PERSPECTIVA CRÍTICA}

A importância dos estudos interdisciplinares revela-se diante das possibilidades da Arte no plano real-existencial como mecanismo de empatia englobante e transmissor do pensamento crítico. Wolkmer (2015) alude às tendências inovadoras que rondam a Teoria Crítica do Direito. Urge que essas tendências sejam orientadas por uma redefinição da racionalidade e um novo fundamento epistêmico - tanto nas Ciências Humanas quanto no mundo do Direito.

[...] a linearidade histórico-social do pensamento jurídico-filosófico contemporâneo é marcada, nas últimas décadas, por múltiplas tendências inovadoras, compartilhadas por ideias, autores e escolas, e que acaba reforçando a convicção da profunda crise dos valores, a necessária redefinição da racionalidade que sustenta o 
saber oficial dominante de tradição iluminista, a obrigatoriedade de se buscar um outro fundamento epistêmico e, por derradeiro, a inegável significação de que se reveste, presentemente, a emergência do pensamento crítico (teórico-prático) nas ciências humanas e no mundo do Direito (WOLKMER, 2015, p. 269).

Evidencia-se a necessidade emergencial do pensamento crítico (teórico-prático) envolver e ser absorvido pelas (e nas) Ciências Humanas e Jurídicas. Ao constatar a Arte como "expressão" forjada por sentimentos e perspectivas do "homem" sobre a realidade na qual está imerso, a "contaminação" do intérprete é nada mais do que a interpretação e absorção das visões de mundo.

Nas palavras de Streck e Trindade (2013, p. 228): "olhando a operacionalidade, a realidade não nos toca; as ficções, sim". A literatura compreende uma entre muitas manifestações artísticas de significativo teor epistêmico, social e afetivo. Assim sendo, ao reconhecer a literatura como Arte, alude-se que ela representa uma dimensão disruptiva em relação ao positivismo, oferecendo grande possibilidade de revisão do pensamento crítico social e acadêmico/jurídico. Santos (2012, p. 33) considera que "a relação entre Direito e Literatura se instaura no percurso metodológico e da pesquisa acadêmico-científica como possibilidade de abertura a novos horizontes, que permitam reflexão crítica acerca de fenômenos sociais e jurídicos que se interpenetram".

A Arte em sua expressão literária teria, então, o papel de inscrever diferentes perspectivas, oferecendo condições para reflexão crítica a respeito de fenômenos sociais e jurídicos.

A obra de arte está se tornando cada vez mais, de Joyce à musica serial, da pintura informal aos filmes de Antonioni, uma obra aberta, ambígua, que tende a sugerir não um mundo de valores ordenado e unívoco, mas uma rosa de significados, um "campo" de possibilidades, e que, para obtê-lo, exige cada vez mais uma intervenção ativa, uma escolha operativa por parte do leitor ou espectador (ECO, 2016, p. 271).

Com alusão à operacionalidade mencionada por Streck e Trindade (2013) e tomando por base a teoria artística contemporânea de Eco (2016), constata-se o papel crítico proporcionado pela Arte, abrindo um "campo" de possibilidades de escolhas operativas e críticas do espectador/leitor/intérprete.

A Arte pode manifestar a crítica de modo indireto nas expressões plásticas, como é o exemplo da obra $A$ Última Ceia de Marcos Zapata, exposta na Catedral de Cuzco, no Peru.

Figura 1 - A Última Ceia de Marcos Zapata

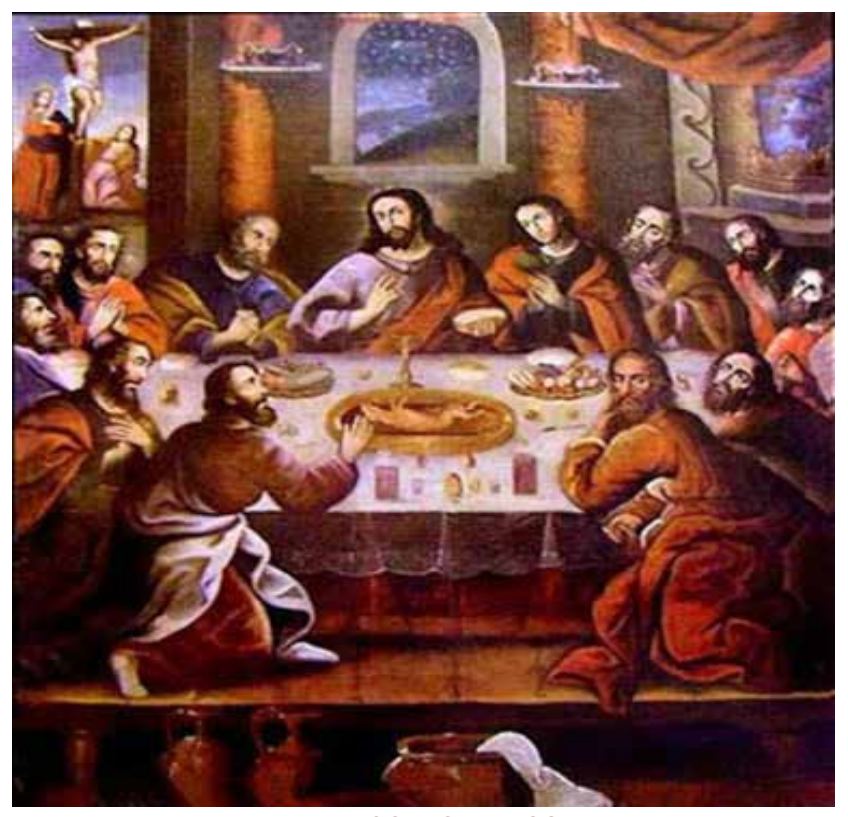

Fonte: BISCALCHIN, 2017.

Esta obra apresenta, em substituição ao pão (clássica alegoria ao "corpo" na tradição judaico-cristã), um "Cuy assado" (porquinho da índia), uma iguaria servida em Cuzco. Há também a substituição do vinho (alegoria ao "sangue") por garrafas de "chicha", uma bebida derivada do milho, também tradicional de Cuzco. Por fim, em substituição a Judas, a obra retrata Francisco Pizarro, colonizador do Peru (BISCALCHIN, 2017). O 
senso crítico da obra paira em torno do descolonialismo, que busca(va) a desconstrução e emancipação do modelo destrutivo da cultura clássica peruana diante do modelo eurocêntrico, pensamento ainda muito predominante na Teoria Crítica - principalmente com recorte às epistemologias e realidades latino-americanas.

A literatura, por sua vez, conforme observa Coutinho (1978, p. 9-10), "é uma transfiguração do real, é a realidade recriada através do espírito do artista e retransmitida através da língua para as formas, que são os gêneros, e com os quais ela toma corpo e nova realidade". Na condição de transfiguração do real e como expressão, a literatura pode facilmente manifestar críticas direcionadas e oriundas da sociedade. Obras clássicas, como Os Miseráveis, de Victor Hugo (2014), que trava um embate direto contra os ideais exegéticos de um univocismo semântico; Frankenstein, de Mary Shelley (2014) que, ao buscar conscientização sobre as diferenças, metaforiza o "monstro" tomado pela humanidade como "o diferente", o que é, por si só, uma severa crítica à forma como a humanidade tem dialogado e conformado a modernidade; Fausto, de Johann Wolfgang von Goethe (1948), que demonstra a fácil cadência humana em se deixar desvirtuar pela influência do coletivo. Cumpre mencionar também obras voltadas à realidade brasileira/latino-americana, como $O$ Auto da Compadecida, de Ariano Suassuna (2016), que demonstra intensa crítica ao formalismo positivista; $A$ Escrava Isaura, de Bernardo Guimarães (1995), que trava uma dura luta contra a cultura escravista, entre outras que revelam grande valor em perspectiva criticista, seja na esfera social e/ou jurídica.

Como corrente literária, também merecem comento neste estudo as histórias em quadrinhos, seja por seu aprofundamento dinâmico em temáticas diversas seja por sua qualidade didática. Obras contemporâneas que demonstram tal relação de forma substancial e podem ser tomadas como exemplo: A Diferença Invisível, de Mademoiselle Caroline e Julie Dachez (2017), que trata sobre o espectro autista; Não era você que eu esperava, de Fabien Toulmé (2018), que aborda a Trissomia do 21 (Síndrome de Down); Pílulas Azuis, de Frederik Peeters (2015), que discorre sobre a imunodeficiência humana (Aids); Desconstruindo uma, de Una (2016), que versa sobre a discriminação e violência de gênero, Angola Janga, de Marcelo D'Salete (2017), que trata sobre o colonialismo eurocêntrico e racismo.

Há, evidentemente, uma infinidade de obras que oportunizam reflexões profundas no campo literário. $\mathrm{O}$ quadro citado alinha-se à proposta das professoras Naspolini e Grossi, na medida em que estas obras conscientizam seus "espectadores" sobre questões sociais, por intermédio de metodologias, por natureza, mais sensoriais e empáticas. Para além da literatura, cumpre mencionar uma das expressões típicas do Brasil, seja por seu caráter crítico ímpar, seja por representar um vetor de resistência da cultura periférica brasileira: o carnaval. Considerando os diversos conflitos advindos do contexto político e social do país, o carnaval de 2019 foi uma expressão de criticidade notável da história recente, em maior escala percebida na proposta da Estação Primeira de Mangueira. O desfile da escola de samba contou com elementos que evidenciaram crimes de grande repercussão, como o assassinato de Marielle Franco, personagens históricos brasileiros considerados "heróis esquecidos ou invisibilizados", bem como líderes brasileiros durante o período da ditadura militar. A crítica rendeu à escola de samba o título do carnaval carioca (GALDO, 2019), assim como a repercussão internacional destas inquietudes sociais.

O acervo artístico disponível é imenso quando se trata de manifestação de pensamento crítico. Evidencia-se a pluralidade de formas, de obras literárias às expressões audiovisuais; emerge também o movimento musical do Rap (Hip-Hop), o qual abre inúmeras possibilidades de intervenções, operacionalidades, "contaminação" e manifestação de pensamento crítico. De acordo com Massoni e Fernandes (2005), este movimento "originou-se no Bronx, bairro periférico de Nova York por volta da década de 70" como uma resposta aos "conflitos políticos ocorridos na década de 60, por exemplo, as leis segregacionistas e a discriminação do negro" que, por si só, acabou por propiciar "a manifestação e o protesto da população marginalizada através da música, da rima, da dança e da arte". Importa observar o contexto no qual o este movimento se insere: "analisamos o rap no contexto da Poesia Oral por entendermos que ele expressa a realidade vivida na periferia e nas favelas da cidade, ou seja, utiliza um contexto coletivo e suas manifestações são mais comuns do que pessoais" (MASSONI; FERNANDES, 2005). Neste sentido "o rap não pode ser analisado sem considerar o contexto no qual está inserido, 'isto é, da pessoa que as(o) interpreta, do ato de interpretar e, sobretudo, da situação de vida e de convivência, em função das quais foram elaboradas e são executadas'" (CANDIDO apud MASSONI; FERNANDES, 2005). 
Algumas letras de músicas brasileiras de Hip-Hop denunciam o contexto do qual emergem e as várias faces das inquietações vivenciadas por seus autores e intérpretes. Dois exemplos contemporâneos de expressiva presença nas redes de comunicação podem ser mencionados: "Rap News", de MC Sid, e "O Rap é Preto", de Fabio Brazza.
Serviço público é regido na incompetência
O país laico é mais religião do que ciência
E ter uma bancada evangélica racista e homofóbica
É sinal dessa democracia em decadência (SID, 2017).
Salário é mixaria, se aposentar é utopia
Mas chegar na velhice já é lucro pra quem vive na periferia
Eu preferia tomar um 7 a 1 todo dia
Do que ver esses 171 roubando nossa aposentadoria (BRAZZA, 2017).

Os trechos citados demonstram com clareza tanto a criticidade do movimento quanto a necessidade de se inserir minimamente na realidade na qual o autor está exposto para compreender o sentido da mensagem. Isso posto, voltando à base interdisciplinar da discussão, em consonância com os entendimentos supracitados, Coelho (2003, p. 336) observa que

[...] o objetivo almejado pela teoria crítica do Direito é uma visão realista a partir da sociedade, e não o inverso. Trata-se de um novo realismo, não o do senso comum, acomodado com as coisas dadas, mas um realismo crítico, propondo-se ao repensar e à rediscussão da função social do direito e dos juristas, dentro do espírito de renovação que sempre animou as faculdades de direito.

Em consonância com os exemplos citados pode-se afirmar que a Teoria Crítica do Direito pode proporcionar uma visão mais ampla ao intérprete, desconstruindo percepções dogmáticas ou de senso comum. Nesse sentido, é importante a observação de fontes reflexivas e empáticas, para que o intérprete possa ter uma visão mais sensitiva das questões em apreço. Como já citado, observa Eco (2016, p. 272), "a arte é uma forma de atividade que estabelece uma relação dialética com outras atividades, outros interesses e outros valores". As expressões artísticas encontram espaço para dialogar com as expressões do Direito. A Teoria Crítica do Direito pode valer-se da Arte para seu desenvolvimento, de modo a promover o esclarecimento de obscuridades a respeito dos fenômenos sociais contemporâneos.

\section{CONCLUSÃO}

À guisa de conclusão, cabe considerar que a Arte se relaciona com o Direito - assim como o reproduz de forma que o pensamento crítico pode integrar-se a esta relação. Entender o Direito crítico em determinado contexto cultural é entender que a Arte, em sua perspectiva e alcance, também aporta a criticidade insurgente, pois trata-se de um movimento transformador cultural, e não algo aprisionado a uma determinada base epistêmica.

Quanto à interdisciplinaridade e relação que as duas áreas fomentam, vale recordar o estudo de Naspolini e Grossi (2017), que registra como a Arte proporciona um senso de empatia ao intérprete, contribuindo para a compreensão da realidade social. Desenvolver um senso de empatia, por sua vez, é fundamental para a convivência e, principalmente, para oportunizar o pensamento crítico com relação à sociedade. Nestes termos, alinha-se o Direito ao marco da criticidade.

O Direito é tradicionalmente reconhecido como a expressão do paradigma coercitivo do "dever ser". Com o advento da Teoria Crítica, a tônica consiste no "dever ser" relacionado ao "ser", aproximando a realidade, antes alheia ao positivado. Neste contexto, a Arte e o Direito, na condição de paradigmas de expressões variadas, podem se relacionar, observar e complementar reciprocamente. Conforme alude Pessoa (1966, p. 30), "O fim da arte inferior é agradar, o fim da arte média é elevar, o fim da arte superior é libertar". 
De tal forma, a Arte oportuniza a reflexão e a disseminação do pensamento crítico, participando da epistemologia jurídica de modo interdisciplinar, oportunizando renovações no Direito. Juntas, ambas possibilitam a emancipação e transformação cultural, o que, por si só, integra-se ao âmago da crítica como categoria epistêmica de relevância social.

\section{REFERÊNCIAS}

BENJAMIN, Walter. A obra de arte na era da sua reprodutibilidade técnica. In: VERLAG, Suhrkamp (org.). Walter Benjamin magia e técnica, arte e política: ensaios sobre literatura e história da cultura. 3. ed. São Paulo: Brasiliense, 1987.

BISCALCHIN, Fabio Camilo. A última ceia: Marcos Zapata (Século XVIII) - Catedral de Cusco (Peru). 2017. Disponível em: http:// biscalchineditor.com.br/wp-content/uploads/2017-01-25_Última-Ceia-Marcos-Zapata-Sec-XVIII---Catedral-de-Cusco-Peru. pdf. Acesso em: 10 mar. 2019.

BOBBIO, Norberto. O positivismo jurídico: lições de filosofia do direito. São Paulo: Ícone, 2006.

BRAZZA, Fabio. O rap é preto. In: BRAZZA, Fabio. É ritmo mas também é poesia. São Paulo: AMG Estúdio; Casa1, 2017.

CAPITÃO FANTÁSTICO. Direção: Matt Ross, Produção: Jamie Patricof, Lynette Howell, Samantha Housman. Manaus (AM): Universal Pictures, 2016, 1 DVD.

CAROLINE, Mademoiselle; DACHEZ, Julie. A diferença invisível. Tradução Fernando Scheibe. São Paulo: Nemo, 2017.

COELHO, Luiz Fernando. Teoria crítica do direito. 3. ed. Belo Horizonte: Del Rey, 2003.

COUTINHO, Afrânio. Notas de teoria literária. 2. ed. Rio de Janeiro: Civilização Brasileira, 1978.

CRISTELLI, Paulo. J. R. R. Tolkien e a crítica à modernidade. São Paulo: Alameda, 2013.

D’SALETE, Marcelo. Angola Janga: uma história de Palmares. São Paulo: Veneta, 2017.

ECO, Umberto. A definição de arte. Tradução Eliana Aguiar. Rio de Janeiro: Record, 2016.

FISCHER, Ernst. A necessidade da arte. Rio de Janeiro: Zahar, 1979.

GALDO, Rafael. Mangueira é campeã do carnaval carioca com o avesso da História do Brasil, O Globo, 6 mar. 2019. Disponível em: https://oglobo.globo.com/rio/mangueira-campea-do-carnaval-carioca-com-avesso-da-historia-do-brasil-23503003. Acesso em: 12 mar. 2019.

GOETHE, J. W. Fausto. Rio de Janeiro: W. M. Jackson Inc., 1948.

GUIMARÃES, Bernardo. A escrava Isaura: texto integral. 21. ed. São Paulo: Ática, 1995.

HUGO, Victor. Os Miseráveis. Tradução Regina Célia de Oliveira. Edição especial. São Paulo: Martin Claret, 2014.

KOBS, Verônica Daniel. Dadaísmo e surrealismo: zonas fronteiriças da relação interartes. Todas as Musas, ano 1, n. 2, jan./jul. 2010. Disponível em: https://www.todasasmusas.org/02Veronica_Daniel.pdf. Acesso em: 10 fev. 2019.

MASSONI, Andressa; FERNANDES, Frederico A. G. Hip hop e rap: história e manifestações orais no contexto londrinense, 2005. Disponível em: http://www.snh2011.anpuh.org/resources/anais/anpuhnacional/S.23/ANPUH.S23.0121.pdf. Acesso em: 12 mar. 2019.

MORIN, Edgar. Introdução ao pensamento complexo. 4. ed. Porto Alegre: Sulina, 2011.

NASPOLINI, Mariza; GROSSI, Miriam Pillar. Corpo, gênero e performance: uma experiência de alteridade a partir da escola. Cadernos de Gênero e Diversidade, v. 3, n. 3, 2017, p. 84-92. Disponível em: http://dx.doi.org/10.9771/cgd.v3i3.23660. Acesso em: 5 nov. 2018.

ORDINE, Nuccio. A utilidade do inútil: um manifesto. Rio de Janeiro: Zahar, 2016.

PEETERS, Frederik. Pílulas azuis. Tradução Fernando Scheibe. São Paulo: Nemo, 2015.

PESSOA, Fernando. Páginas de estética e de teoria literárias. Lisboa: Ática, 1966.

RUGIU, Antonio Santoni. Nostalgia do mestre artesão. Campinas: Autores Associados, 1998.

SANTOS, Silvana Maria Pantoja. Direito e literatura: perspectiva transdisciplinar na abordagem de temas sociais e jurídicos. Interfaces Científicas, Aracaju, v. 1, n. 1, p. 33, 2012. Disponível em: http://dx.doi.org/10.17564/2316-381X.2012v1n1p27-34. Acesso em: 10 fev. 2019.

SCREMIN, Mayra de Souza. Do Positivismo Jurídico à Teoria Crítica do Direito. Revista da Faculdade de Direito da UFPR, v. 40, n. 1, p. 149-162, 2004. Disponível em: http://revistas.ufpr.br/direito/article/viewFile/1740/1439. Acesso em: 12 mar. 2019.

SHELLEY, Mary. Frankenstein ou o Prometeu moderno. Tradução Adriana Lisboa. 2. ed. Rio de Janeiro: Nova Fronteira, 2014.

SID, MC. Rap News. In: SID, Mc. Single. São Paulo: Casa 1, 2017.

STRECK, Lênio; TRINDADE, André K. (org.). Direito e literatura: da realidade da ficção à ficção da realidade. Porto Alegre: Atlas, 2013.

SUASSUNA, Ariano. Auto da compadecida. 36. ed. Rio de Janeiro: Nova Fronteira, 2016. 
TOLSTOI, Leon. O que é arte? A polêmica visão do autor de Guerra e Paz. 2. ed. Rio de Janeiro: Nova Fronteira, 2016. TOULMÉ, Fabien. Não era você que eu esperava. Tradução Fernando Scheibe. São Paulo: Nemo, 2018.

TRILLING, Lionel. A mente no mundo moderno. São Paulo: É Realizações, 2015.

UNA. Desconstruindo Una. Tradução Fernando Scheibe. São Paulo: Nemo, 2016.

WOLKMER, Antonio Carlos. Introdução ao pensamento jurídico crítico. 9. ed. São Paulo: Saraiva, 2015. 